\title{
Lectin Histochemistry Reveals Changes in Carbohydrate Expression on Morphological Types of Breast Ductal Carcinoma in situ
}

\section{Gabriela Souto Vieira-de-Mello ${ }^{1 \#}$, Antônio Felix da Silva Filho'”\#, Petra Barros dos Santos ${ }^{1}$, Moacyr Jesus Barreto de Melo Rêgo ${ }^{1}$ and Eduardo Isidoro Carneiro Beltrão ${ }^{1,2 *}$}

${ }^{1}$ Laboratório de Imunopatologia Keizo Asami (LIKA), Universidade Federal de Pernambuco, Cidade Universitária, Recife, Pernambuco, Brazil.

${ }^{2}$ Departamento de Bioquímica, Centro de Ciências Biológicas, Universidade Federal de Pernambuco, Cidade Universitária, Recife, Pernambuco, Brazil.

\# Both authors contributed equally

\begin{abstract}
Breast Ductal Carcinoma in situ (DCIS) show a high degree of architectural heterogeneity and what kind of DCIS lesions will progress to invasive disease remains unknown. Thus, its characterization remains a complex process. In addition, in the same tumor we can find different types of lesions that presented different biological behaviour and morphology. Carbohydrate expression changes play crucial roles in carcinogenesis of the breast, becoming the study these changes a useful tool for an accurate predictor. In this context, this work aimed analyzed the differential expression of specific carbohydrates among the DCIS lesion through lectin histochemistry and its correlation with its behaviors. Glycobiology expression of $218 \mathrm{DCIS}$ samples of human breast cancer was investigated by MAL-II, PNA, WGA, PHA-L and SNA lectins. MAL-II was more expressed ( $p=0.0191)$ in cribriform (positive in $100 \%)$ than in comedo (positive in $41.2 \%)$ and solid lesions $(p=0.0440)$. However, PNA profile showed a higher reactivity in comedo $(p=0.0052)$ and micropapillary $(p=0.0010)$ lesions when compared to solid one. The other lectins showed different expression degrees in all lesions analyzed but none was statistically relevant. Our results revels different carbohydrate patterns concerning different DCIS morphological subtypes indicating that these lesions could act as independent biological entities.
\end{abstract}

Keywords: Ductal carcinoma in situ; Breast cancer; Glycobiology; Lectin histochemistry; Tumoral morphology

\section{Introduction}

Among women, breast cancer is the most common type and is the leading cause of cancer deaths in world [1]. In past few decades the mammography screening programs have design a new breast tumors profile frequency, when Ductal Carcinoma in situ (DCIS) stands out among them showing an increase in their occurrence due to the increase of early diagnosis. However this type of lesion is still poorly studied. The few studies available show contradictory results when compared to invasive ductal carcinoma, especially regarding to whether or not subtypes of DCIS lesions may progress to the invasive disease [2-4]. DCIS study is challenged by the presence of a high degree of architectural and morphological heterogeneity in their lesions. In this scenario their lesions are segregated into different histopathological groups classified as comedo (which often presents central necrosis and calcification), solid (presenting ducts filled by neoplastic cells where there is no necrosis), cribriform (with small holes or open spaces in ducts) and micropapillary (featuring finger-like projections) [5]. Commonly, a mix of theses lesions is found in the same tumor; however each of these histological lesion subtypes has a different prognosis [6].

In homeostasis, cells express surface proteins that undergo posttranslational modifications which glycosylation stands as one of the most important event mediated by the action of glycosyltransferases. This carbohydrate profile is implicated in the regulation of several important physiological processes such as adhesion, signal transduction and biological recognition besides mediate cell-cell interactions and cell-matrix [7].

The human glycode is of particular interest in cancer research given that altered glycans, produced by an interrupted glycosylation, are a common feature of a broad variety of tumor types $[7,8]$. Lectin histochemistry has been used in the medical and biological areas as a tool to investigate these altered surface carbohydrates [9], in meningothelial tumour [10], in fetal minor salivary glands [11] and parotid gland mucoepidermoid carcinoma [12]. Thus, a better understanding of the cell surface glycocode of each DCIS lesion is an initial step in identifying the reasons that lead some lesions to progress to invasive behavior. For this, the present study evaluated the expression pattern of different types of carbohydrates in DCIS subtype lesions using lectin histochemistry.

\section{Materials and Methods}

\section{Specimens}

We performed a per-lesion basis analysis of breast ductal carcinoma in situ. The 218 analyzed lesions were classified according to the architectural pattern as comedo, solid, cribriform and micropapillary according to Bellamy [13] and Page [14]. Samples and clinic-histopathological data were obtained from the tissue archives of Pathology Service at Hospital das Clínicas (HC) from the Federal University of Pernambuco (UFPE) after approval by Health Sciences Centre Ethics Board. Cases of DCIS associated with IDC were excluded.

\section{Lectin histochemistry}

Four micrometer thick specimens sections were deparaffinized in xylene and hydrated in graded series of alcohol (100-70\%). Slices were

*Corresponding author: Dr.Eduardo Beltrão, Universidade Federal de Pernambuco, Laboratório de Imunopatologia Keizo Asami-LIKA/UFPE, Av. Prof. Moraes Rego, s/n, Campus Universitário, Recife, Pernambuco, 50670 490, Brazil, Fax: +55-81-2126-8000; E-mail: ebeltrao@hotmail.com

Received July 11, 2013; Accepted July 26, 2013; Published July 30, 2013

Citation: Vieira-de-Mello GS, da Silva Filho AF, dos Santos PB, de Melo Rêgo MJB, Beltrão EC (2013) Lectin Histochemistry Reveals Changes in Carbohydrate Expression on Morphological Types of Breast Ductal Carcinoma in situ . J Cytol Histol 4: 179. doi:10.4172/2157-7099.1000179

Copyright: (C) 2013 Vieira-de-Mello GS, et al. This is an open-access article distributed under the terms of the Creative Commons Attribution License, which permits unrestricted use, distribution, and reproduction in any medium, provided the original author and source are credited. 
treated with $0.1 \%(\mathrm{w} / \mathrm{v})$ trypsin solution for $15 \mathrm{~min}$ at $37^{\circ} \mathrm{C}$ and with a $0.3 \%(\mathrm{v} / \mathrm{v})$ methanol- $\mathrm{H}_{2} \mathrm{O}_{2}$ solution for $30 \mathrm{~min}$ at $25^{\circ} \mathrm{C}$ according to Beltrão [10]. After that, samples were incubated, separately, with the biotin conjugated lectins (Maackia amurensis agglutinin (MAL-II), Arachis hypogaea agglutinin (PNA), Wheat germ agglutinin (WGA), Phaseolus vulgaris leucoagglutinin (PHA-L) and Sambucus nigra Agglutinin (SNA)-Vector Laboratories Inc., Burlingame, CA, USA) at $70 \mu \mathrm{g} / \mathrm{mL}$ for $2 \mathrm{~h}$ at $4^{\circ} \mathrm{C}$. For PHA-L lectin after trypsin treatment slides were incubated with a $0.1 \mathrm{U} / \mathrm{mL}$ neuraminidase solution from Clostridium perfringens (Sigma Aldrich, Missouri, USA), for $1 \mathrm{~h}$ at $37^{\circ} \mathrm{C}$. After washes with $100 \mathrm{mM}$ phosphate buffer solution (PBS), $\mathrm{pH}$ 7.2 , containing $150 \mathrm{mM} \mathrm{NaCl}$, slides were incubated with streptavidinperoxidase polymer (Sigma Aldrich, Missouri, USA) for $45 \mathrm{~min}$ at $25^{\circ} \mathrm{C}$. The reaction was revealed with diaminobenzidine (DAB) and counterstained with hematoxylin (PBS was used to prepare all solutions and as washing solution between each step). Negative controls were performed replacing the lectin for PBS. Histochemistry staining was independently analyzed by two pathologists and cases with discrepant scores were reevaluated jointly. The staining intensity was determined by previously study established by Lima [15] as the pattern observed in at least $20 \%$ of cells with cytoplasm or membrane staining in four categories: $0=$ no staining, $1=$ weak staining, $2=$ moderate staining and $3=$ intense staining. For statistical analysis, we dichotomized as negative $(0$ and $1+)$ and positive $(2+$ and $3+)$ following previously studies [16,17]. Tissue sections were examined using Olympus microscope optic Eclipse 50i (Tokyo, Japan) and an Image Analyses System (software NIS-Elements F version 2.30-Nikon, USA) was used for image acquisition.

\section{Statistical analysis}

Data analysis was performed with GraphPad Prism 6.0 (San Diego, CA, USA) using a p-value $<0.05$ as significant. The relationships between lectin staining and the DCIS morphological classification were analyzed by two-tailed Fisher Exact Test.

\section{Results}

The distribution of the lesions per lectin is showed in (Table 1). MAL-II and PNA presented a significant correlation between lectin staining and lesions subtypes. MAL-II results (Figures 1 and 2) revealed that $\alpha-2,3$-sialic acid expression was increased $(\mathrm{p}=0.0191)$ in cribriform (positive in $100 \%$ of analyzed lesions) in comparison to comedo (positive in 41.2\%) subtype, in addition, the expression of this carbohydrate also increased in cribriform compared to solid $(44.4 \%$ positive samples) lesions ( $\mathrm{p}=0.0440)$. The relationship between the staining pattern of the four subtypes of DCIS lesions and PHA-L, SNA and WGA showed no significant correlation.

\begin{tabular}{|l|c|c|c|c|c|}
\hline \multirow{2}{*}{ Lectins } & Status & Comedo & Micropapillary & Cribriform & Solid \\
\cline { 2 - 6 } & & $\mathbf{n}(\%)$ & $\mathbf{n ~ ( \% )}$ & $\mathbf{n}(\%)$ & $\mathbf{n}(\%)$ \\
\hline \multirow{2}{*}{ PHA-L } & Positive & $16(94.1)$ & $4(100)$ & $6(100)$ & $6(100)$ \\
& Negative & $1(5.9)$ & $0(0)$ & $0(0)$ & $0(0)$ \\
\hline \multirow{2}{*}{ MAL-II } & Positive & $7(41.2)$ & $4(100)$ & $6(100)$ & $4(44.4)$ \\
& Negative & $10(58.8)$ & $0(0)$ & $0(0)$ & $5(55.6)$ \\
\hline \multirow{2}{*}{ PNA } & Positive & $17(73.9)$ & $11(91.7)$ & $6(66.7)$ & $3(23.1)$ \\
& Negative & $6(26.1)$ & $1(8.3)$ & $3(33.3)$ & $10(76.9)$ \\
\hline \multirow{2}{*}{ SNA } & Positive & $14(93.3)$ & $4(100)$ & $5(83.3)$ & $7(87.5)$ \\
& Negative & $1(6.7)$ & $0(0)$ & $1(16.7)$ & $1(12.5)$ \\
\hline \multirow{2}{*}{ WGA } & Positive & $17(70.9)$ & $6(60)$ & $10(71.4)$ & $7(63.6)$ \\
& Negative & $7(29.1)$ & $4(40)$ & $4(28.6)$ & $4(36.4)$ \\
\hline
\end{tabular}

Semi-quantitative analysis of the lectin histochemistry staining to morphological subtypes of DCIS.

Table 1: Lectin histochemistry per CDIS lesions status.
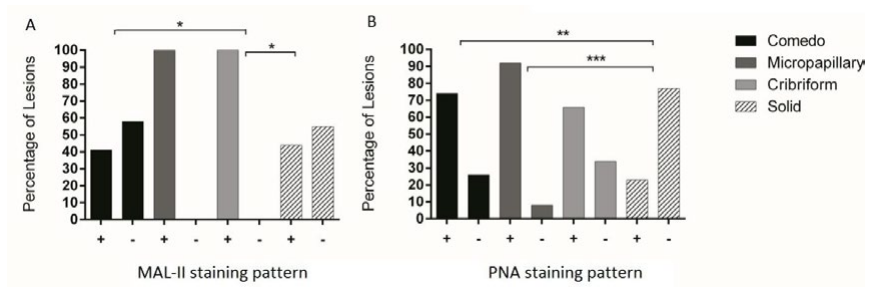

Figure 1: MAL-II and PNA histochemistry per DCIS lesions status.

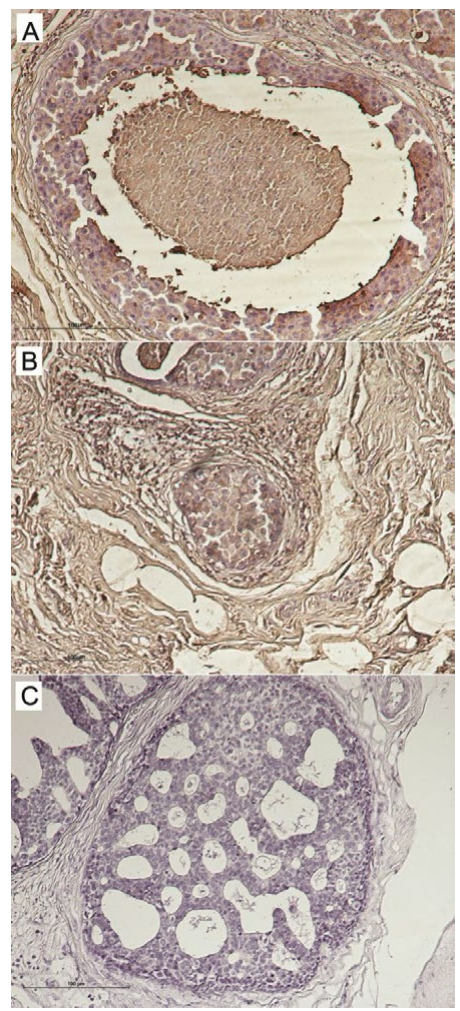

Figure 2: MAL-II Histochemistry.

The expression of $\beta-1-3-\mathrm{N}$-acetylgalactosamine, recognized by PNA (Figure 3), was increased in both lesions comparisons, comedo (positive in $73.9 \%$ ) versus solid (positive in $23.1 \%$ ) with a $\mathrm{p}=0.0052$ and micropapillary (positive in $91.7 \%$ ) versus solid (positive in $23.1 \%$ ) with a $\mathrm{p}=0.0010$.

\section{Discussion}

Our results showed that different types of DCIS lesions exhibit not only a broad range of differentiation in terms of conventional histologic grades, but also a specific pattern of carbohydrate expression which may help to differentiate the subtypes in a histochemistry way. The presence of necrosis in DCIS lesions, characteristic of comedo/highgrade type, pursue a different course of evolution [18], presenting a more aggressive behavior compared with non-comedo lesions. Comedo type DCIS showed a much higher rate of short-term local recurrence and it is more histologically similar to invasive disease than is the noncomedo-type $[2,19]$.

The comedo-type cell behavior may be related to the carbohydrate expression pattern changes found among the lesions as shown by our results. Besides individual genome alterations in cycle cell controlling 


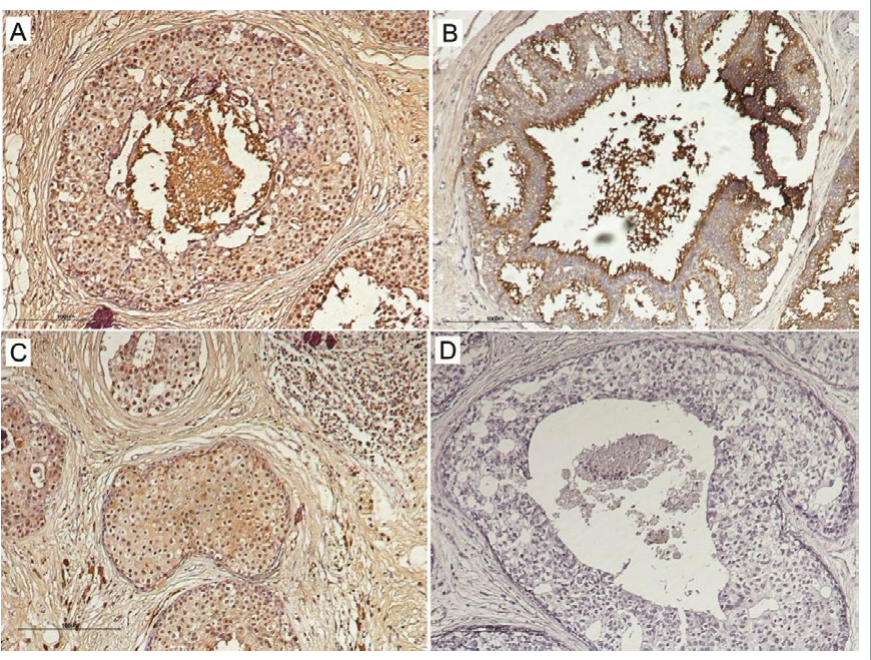

Figure 3: PNA Histochemistry.

genes glycosyltransferases and glycosylhydrolases genes, responsible for the addition and removal of sugars on proteins in the ER and Golgi apparatus, can change activity during oncogenesis, causing different oligosaccharide structures to emerge on cell surface glycoproteins [20].

Our results suggest that $\alpha-2,3$-sialic acid (recognized by MAL-II) and $\beta-1,3-\mathrm{N}$-acetylgalactosamine (recognized by PNA) expression patterns changed in response to the necrosis presence. The first carbohydrate exhibited a decrease in its expression on comedo lesions compared to cribriform lesions (non-comedo), contrasting with an increase in expression of $\beta-1,3-\mathrm{N}$-acetylgalactosamine in comedo compared to solid lesions.

Altered sialylation is one of the most striking features of several tumors and the specific $\alpha-2,6$ sialylation has most often been associated with poor prognosis, once that is directly connected with migration and invasion $[21,22]$. In our results $\alpha-2,3$ sialylation, recognized by MALII, was predominant in cribriform lesions, while SNA results showed a predominance of $a-2,6$ sialylation in comedo and micropapillary lesions, despite the fact that presented no statistical relevance.

The results suggest that DCIS may have a prognosis when an early high degree of $a-2,6$ sialylation is observed. Moreover, since it is not possible to predict individually whether or not a lesion will progress to an invasive form lectin histochemistry presents that the different carbohydrate pattern found in DCIS can help to understand a possible behavior and further can help to classify the tumor as a unique entity despite the broad diagnosis of DCIS.

The altered expression of both carbohydrates recognized by PHA-L and WGA has already been shown to be involved in numerous cellular pathways as adhesion, motility, angiogenesis, and apoptosis [23]. A higher expression of these carbohydrates was observed in all subtypes of lesions.

According to Allred [18] in the majority of DCIS cases there is a gradual change from well-differentiated to poorly differentiated lesions, suggesting diversity within individual lesions at some point. Our results provide new insights into DCIS subtypes demonstrating that the different carbohydrate profile between them may help to understand the progression and relationship between benign and malignant lesions.

The present work showed that the DCIS subtypes present not only a morphological difference but also that using lectin histochemistry these tumors present a differential carbohydrate expression. Such feature may, to some extent, suggest an individual identity, especially in the presence of necrosis. In addition, the results reinforce the importance of lectins as important scientific tools for detection of changes in phenotype of breast tumors helping to clarify the existence, or not, of a linear progression between low-grade and high-grade DCIS lesions.

\section{Acknowledgments}

Authors thank to Conselho Nacional de Desenvolvimento Científico e Tecnológico (CNPq) and Coordenação de Aperfeiçoamento de Pessoal de Nível Superior CAPES) for financial support and to Msc. Carmelita de Lima Cavalcanti for technical assistance.

\section{References}

1. American Cancer Society (2011) Breast Cancer Facts \& Figures. Atlanta: Inc, 2011.

2. Phillips LS, Millikan RC, Schroeder JC, Barnholtz-Sloan JS, Levine BJ (2009) Reproductive and hormonal risk factors for ductal carcinoma in situ of the breast. Cancer Epidemiol Biomarkers Prev 18: 1507-1514.

3. Zhang W, Gao EL, Zhou YL, Zhai Q, Zou ZY, et al. (2012) Different distribution of breast ductal carcinoma in situ, ductal carcinoma in situ with microinvasion, and invasion breast cancer. World J Surg Oncol 10: 262.

4. Fota GL, Stepan A, Ciurea RN (2012) The evaluation of the immunoexpression of Her2 $\div$ neu oncoprotein in ductal carcinoma in situ in association with invasive ductal carcinoma of the breast. Rom J Morphol Embryol 53: 805-810.

5. Provenzano E, Brown JP, Pinder SE (2013) Pathological controversies in breast cancer: classification of ductal carcinoma in situ, sentinel lymph nodes and low volume metastatic disease and reporting of neoadjuvant chemotherapy specimens. Clin Oncol (R Coll Radiol) 25: 80-92.

6. Wang SY, Shamliyan T, Virnig BA, Kane R (2011) Tumor characteristics as predictors of local recurrence after treatment of ductal carcinoma in situ: a meta-analysis. Breast Cancer Res Treat 127: 1-14.

7. Kim YS, Kim SH, Kang JG, Ko JH (2012) Expression level and glycan dynamics determine the net effects of TIMP-1 on cancer progression. BMB Rep 45: 623628 .

8. Fry SA, Afrough B, Lomax-Browne HJ, Timms JF, Velentzis LS, et al. (2011) Lectin microarray profiling of metastatic breast cancers. Glycobiology 21: 10601070.

9. Schnegelsberg B, Schumacher U, Valentiner U (2011) Lectin histochemistry of metastasizing and non-metastasizing breast and colon cancer cells. Anticancer Res 31:1589-97.

10. Beltrão El, Medeiros PL, Rodrigues OG, Figueredo-Silva J, Valença MM, et al. (2003) Parkia pendula lectin as histochemistry marker for meningothelial tumour. Eur J Histochem 47: 139-142.

11. RÃ ${ }^{a}$ go MJBM, Cavalacanti CLB, Beltrã£o EIC, Sobral APV (2011) Histochemical localization of carbohydrates in morphological stages of developing human minor salivary glands: a comparative study with cytoskeletal markers. Int J Morphol 29:604-13.

12. Sobral AP, Rego MJ, Cavalacanti CL, Carvalho LB Jr, Beltrão El (2010) ConA and UEA-I lectin histochemistry of parotid gland mucoepidermoid carcinoma J Oral Sci 52: 49-54.

13. Bellamy CO, McDonald C, Salter DM, Chetty U, Anderson TJ (1993) Noninvasive ductal carcinoma of the breast: the relevance of histologic categorization. Hum Pathol 24: 16-23.

14. Page DL, Anderson TJ, Rogers LW (1987) Carcinoma in situ. In: Page DL, Anderson TJ (eds) Diagnostic histopathology of the breast. Edinburgh, UK Churchill Livingstone, pp 157-92.

15. de Lima AL, Cavalcanti CC, Silva MC, Paiva PM, Coelho LC, et al. (2010) Histochemical evaluation of human prostatic tissues with Cratylia mollis seed lectin. J Biomed Biotechnol 2010: 179817

16. dos Santos PB, Zanetti JS, Ribeiro-Silva A, Beltrão El (2012) Beta integrin predicts survival in breast cancer: a clinicopathological and immunohistochemical study. Diagn Pathol 7: 104. 
Citation: Vieira-de-Mello GS, da Silva Filho AF, dos Santos PB, de Melo Rêgo MJB, Beltrão EC (2013) Lectin Histochemistry Reveals Changes in Carbohydrate Expression on Morphological Types of Breast Ductal Carcinoma in situ . J Cytol Histol 4: 179. doi:10.4172/2157-7099.1000179

Page 4 of 4

17. Petricevic B, Vrbanec D, Jakic-Razumovic J, Brcic I, Rabic D, et al. (2012) Expression of Toll-like receptor 4 and beta 1 integrin in breast cancer. Med Oncol 29: 486-494.

18. Allred DC, Wu Y, Mao S, Nagtegaal ID, Lee S, et al. (2008) Ductal carcinoma in situ and the emergence of diversity during breast cancer evolution. Clin Cancer Res 14: 370-378.

19. Yagata H, Harigaya K, Suzuki M, Nagashima T, Hashimoto H, et al. (2003) Comedonecrosis is an unfavorable marker in node-negative invasive breast carcinoma. Pathol Int 53: 501-506.

20. Virnig BA, Tuttle TM, Shamliyan T, Kane RL (2010) Ductal carcinoma in situ of the breast: a systematic review of incidence, treatment, and outcomes. J Natl Cancer Inst 102: 170-178.

21. Chen G, Zou Q, Yang Z (2010) [Expression of galectin-3 and Sambucus nigra agglutinin and its clinicopathological significance in benign and malignant lesions of breast]. Zhong Nan Da Xue Xue Bao Yi Xue Ban 35: 584-589.

22. Swindall AF, Bellis SL (2011) Sialylation of the Fas death receptor by ST6Gal-I provides protection against Fas-mediated apoptosis in colon carcinoma cells. J Biol Chem 286:22982â€“90.

23. Handerson T, Pawelek JM (2003) Beta1,6-branched oligosaccharides and coarse vesicles: a common, pervasive phenotype in melanoma and other human cancers. Cancer Res 63: 5363-5369. 